\title{
SISTEMAS DE PRODUÇÃO DE BASE ECOLÓGICA: RE-LOCALIZAÇÃO E REATIVAÇÃO DO ESPAÇO RURAL NO LITORAL NORTE DO RIO GRANDE DO SUL
}

\author{
SISTEMAS DE PRODUCCIÓN DE BASE ECOLÓGICA: RE-LOCALIZACIÓN \\ Y REACTIVACIÓN DEL ESPACIO RURAL EN LA COSTA NORTE DEL RIO \\ GRANDE DO SUL
}

\section{ECOLOGICAL-BASED PRODUCTION SYSTEMS: RE-LOCALIZATION AND REACTIVATION OF THE RURAL SPACE IN THE NORTHERN COAST OF THE RIO GRANDE DO SUL}

\author{
Daniela Garcez ${ }^{1}$ \\ PGDR - Universidade Federal do Rio Grande do Sul \\ garcezd@gmail.com \\ Carlos Guilherme Adalberto Mielitz Netto ${ }^{2}$ \\ PGDR - Universidade Federal do Rio Grande do Sul \\ mielitz@ufrgs.br
}

\section{Resumo}

O cultivo da banana configura-se como uma das produções de maior expressão comercial da Microrregião do Litoral Norte do Rio Grande do Sul. Tal produção apresenta dois grupos de sistemas de cultivo diferenciados, baseados em perspectivas agrícolas distintas, um utilizando preceitos convencionais e outro de base ecológica. Neste trabalho, busca-se entender a economicidade e o funcionamento deste sistema de produção e como este está produzindo a reativação deste espaço rural. Para tanto, apresenta-se uma análise-diagnóstico comparativa dos principais sistemas de produção da banana da referida área. Tal análise foi feita com base na abordagem dos sistemas agrários de Mazoyer e Roudart e no conceito de embeddedness, de acordo com a utilização de Murdoch, Marsden, Banks e Kirwan. Como resultado, seis sistemas de produção foram encontrados. Os indicadores técnicos demonstram que o cultivo ecológico obtém uma eficiência econômica e produtiva relativamente maior. Finalmente, percebe-se que algumas características-chave da agricultura de base ecológica concentram-se na produção de um alimento diferenciado, na tradição e na capacidade de re-socializar ou re-localizar o alimento e dar um novo sentido ao lugar.

Palavras-Chave: Sistemas de Produção; re-localização; embeddedness; bananicultura.

\footnotetext{
${ }^{1}$ Autora. Doutoranda em Desenvolvimento Rural (PGDR/UFRGS); Mestre em Desenvolvimento Rural (PGDR/UFRGS); Licenciada em Geografia (ULBRA).

${ }^{2}$ Orientador e co-autor. Professor Adjunto da Universidade Federal do Rio Grande do Sul; Graduado em Engenharia Agronômica (UFRGS); Mestre em Economia Rural (UFRGS); Doutor em Ciência Econômica (Universidade Estadual de Campinas); Pós-doutorado pela Université de Paris X, Nanterre, em 2002.
} 


\title{
Resumen
}

El cultivo de bananas se configura como la más expresiva producción comercial de la Micro-región de la costa norte del Río Grande do Sul. Dicho cultivo presenta dos diferentes grupos de sistemas, que se basan en distintas perspectivas agrícolas: convencionales y ecológicos. En el presente trabajo, tratamos de entender el desempeño económico y el funcionamiento técnico de este sistema de cultivo y la forma en que está produciendo la reactivación de su espacio rural. Por lo tanto, buscamos presentar un análisis-diagnóstico comparativo de los principales sistemas de producción que se encuentran en la zona. Este análisis se realizó teniendo en cuenta el enfoque de Mazoyer y Roudard, y también se basa en embeddedness, como se ha visto por Murdoch, Marsden, bancos y Kirwan. Como resultado, seis sistemas de producción fueron analizados. En general, los índices técnicos muestran que el cultivo ecológico logra una eficiencia económica y productiva relativamente mayor. Por último, podemos percibir que algunas de las características clave de la agricultura ecológica se centran en la producción de alimentos diferenciada, la tradición y en la capacidad de re-socialización y re-localización de los alimentos, y dan un nuevo significado al lugar.

Palabras-llave: Sistemas de producción; re-localización; embeddedness; cultivo de bananas.

\begin{abstract}
The banana cultivation is configured as the most expressive commercial production of the Northern Coast Micro-region of Rio Grande do Sul. Such cultivation presents two different groups of systems, which are based on distinct agricultural perspectives: conventional and ecological. In this paper, we try to understand the economical performance and the technical operation of that cultivation system and how it is producing the reactivation of its rural space. Thus we present a comparative diagnosisanalysis of the main production systems found in the area. Such analysis was performed taking in account the Mazoyer and Roudard approach, and is also based on embeddedness, as seen by Murdoch, Marsden, Banks and Kirwan. As a result, six production systems were analyzed. In general, the technical indexes show that the ecologic cultivation achieves a relatively higher economic and productive efficiency. Finally, we can perceive that some key-characteristics of the ecological based agriculture are focused on the production of differenced food, tradition and in the food re-socialization or re-localization capability, and they give a new meaning to the place.
\end{abstract}

Keywords: Production systems, re-localization, embeddedness, banana cultivation.

\section{INTRODUÇÃO}

O cultivo da banana configura-se como uma das produções de maior expressão comercial da Microrregião de Osório, situada no litoral norte do Rio Grande do Sul. 
Dedicam-se a ela mais de quatro mil produtores familiares, em propriedades, de pequena extensão de área, que garantem quase toda a produção do estado.

A introdução desta planta foi bem sucedida, nos anos sessenta, graças à artificilialização das condições via insumos agroquímicos (adubos, herbicidas, fungicidas). No Litoral Norte a banana normalmente é cultivada no padrão de monocultura, e, em especial, em pequenas propriedades, o que em certa medida limita o grau de exploração das potencialidades das unidades produtivas. Este fato, em grande parte, tende a agravar a degradação e os fatores limitantes de cunho ambiental, o que muitos autores definem como crise do sistema convencional de produção. Isso, somado ao baixo nível de tecnificação da maioria dos produtores deste cultivo e à falta de recursos, limita a qualidade e a quantidade da produção, ocasionando a descapitalização da unidade produtiva em muitos casos.

Desta forma, não se pode perder a percepção das duas estratégias que talvez tenham sido as mais adotadas por muitas famílias de agricultores do Litoral Norte, as quais consistiam na aceitação da diminuição das condições de reprodução social, com a fragilidade financeira crescente das propriedades, ou no efetivo abandono da terra.

Neste cenário emerge a diferenciação entre dois grupos de sistemas, divergentes e antagônicos, o convencional e o ecológico. O primeiro sistema ${ }^{3}$, de acordo com Gonçalves (2002), é tecnicamente complexo, e o incremento da produtividade está fortemente ligado à utilização da energia de combustíveis fósseis. Assim, apresenta-se biologicamente homogêneo e, em relação ao seu arranjo, demasiadamente simplificado. Como ele está fundamentado num distanciamento do ecossistema original, o seu equilíbrio depende de um conhecimento complexo e específico, além de insumos externos, forte intervenção e controle humano. Ele estaria assim conduzindo a uma crise no equilíbrio natural dos ecossistemas e levando à precariedade da sustentabilidade ambiental.

O segundo sistema ${ }^{4}$, como argumenta Gonçalves (2002), é biologicamente diversificado e estruturalmente complexo. Entretanto, é tecnicamente simples e o seu manejo assenta-se em um conhecimento genérico, com baixo índice de externalidades, fundamentado no desenvolvimento livre dos processos funcionais ocorrentes na vegetação natural, e que se apresentaram sempre pautados no emprego de um valor nulo ou escasso de pesticidas, fungicidas e fertilizantes (fósseis), e na preservação da biodiversidade. Este sistema pode ser exemplificado pelos inúmeros sistemas agrícolas de sociedades tradicionais desenvolvidos em diversas partes do mundo e, como salienta Vivan (2000), no

\footnotetext{
${ }^{3}$ Para fins deste estudo este sistema será denominado de convencional.

${ }^{4}$ Para fins deste estudo este sistema será denominado de base ecológica.
} 
próprio saber "ecológico" destas comunidades.

A área delimitada para realizar este estudo encontra-se na Microrregião de Osório, que é uma das microrregiões do estado do Rio Grande do Sul pertencente à Mesorregião Metropolitana de Porto Alegre. Está dividida em 23 municípios. Para fins do trabalho serão analisados os municípios de Três Cachoeiras, Morrinhos do Sul, Dom Pedro de Alcântara, Mampituba e Torres, sua produção está relacionada no Quadro 1. Ela permite acompanhar a produção bananicultora regional através dos principais municípios envolvidos e destaca a importância econômica e social que este cultivo representa para a Microrregião do Litoral Norte.

Quadro 1. Produção do cultivo de banana por municípios

\begin{tabular}{|l|r|r|r|r|r|}
\hline \multicolumn{1}{|c|}{ Município } & \multicolumn{1}{c|}{$\begin{array}{c}\text { Área } \\
\text { colhida } \\
\text { (ha) }\end{array}$} & \multicolumn{1}{c|}{$\begin{array}{c}\text { Área } \\
\text { definida } \\
\text { (ha) }\end{array}$} & $\begin{array}{c}\text { Qtd. } \\
\text { produção } \\
\text { (ton) }\end{array}$ & $\begin{array}{c}\text { Rendimento } \\
\text { médio } \\
\text { (kg/ha) }\end{array}$ & $\begin{array}{r}\text { Valor da } \\
\text { produção } \\
\text { (R\$/mil) }\end{array}$ \\
\hline Dom Pedro de Alcântara & 550 & 550 & 7.700 & 14.000 & 3.486 \\
\hline Mampituba & 2.200 & 2.200 & 18.700 & 8.500 & 8.466 \\
\hline Morrinhos do Sul & 2.300 & 2.300 & 22.700 & 9.900 & 10.308 \\
\hline Torres & 167 & 167 & 1.670 & 10.000 & 756 \\
\hline Três Cachoeiras & 2.600 & 2.600 & 36.400 & 14.000 & 16.479 \\
\hline Total & $7.817,00$ & $7.817,00$ & $87.170,00$ & $11.280,00$ & $39.495,00$ \\
\hline Produção total do RS & $10.501,00$ & $10.501,00$ & $108.187,00$ & $10.303,00$ & $51.062,00$ \\
\hline \% em relação ao RS & $74,4 \%$ & $74,4 \%$ & $80,6 \%$ & $109,5 \%$ & $77,3 \%$ \\
\hline
\end{tabular}

Fonte: Elaborada pelos autores a partir de dados da FEE (2007).

Pode-se argumentar que a crise deste padrão convencional de cultivo traz à tona a agricultura de base ecológica e, desta forma, a necessidade de gerar subsídios que possam ajudar na discussão que se estabeleceu entre estes distintos sistemas produtivos. Assim, a indagação que norteia este trabalho busca responder qual é o desempenho destes sistemas no que tange às dimensões econômica e produtiva, e como esta se dando o processo de relocalização e a reativação do espaço rural no Litoral Norte do Rio Grande do Sul.

Para tanto, o presente artigo utiliza a metodologia de sistemas agrários de Mazoyer e Roudart (1996) e de embeddedness, de acordo com a utilização de Murdoch, Marsden e Banks (2000) e Kirwan (2004), para viabilizar a compreensão do funcionamento e desempenho dos sistemas de produção ligados ao cultivo da banana e analisar a insurgência do processo de re-localização e as alterações sofridas na Geografia da Microrregião do Litoral Norte do RS. Estando dividido em cinco partes, na primeira seção apresenta-se uma análise da crise do modelo convencional da agricultura e da emergência da agricultura de base ecológica à luz das redes alimentares alternativas. Na segunda 
apresenta-se o conceito de sistema agrário, sistema de produção e de embeddedness. Busca-se ainda sustentar o conceito de embeddedness como uma ferramenta analítica, bem como a sua importância nos estudos rurais. Na terceira, analisa-se os sistemas de produção. Na quarta discute-se o processo de re-localização na Microrregião do Litoral Norte do RS. Na última seção lançam-se alguns apontamentos e sugestões.

\section{CRISE DO MODELO CONVENCIONAL DE PRODUÇÃO}

Nos últimos anos houve uma proliferação de estudos de caso relacionados ao desenvolvimento de modelos alternativos de produção de alimentos. A emergência de redes ou cadeias de alimentos alternativos é comumente conceitualizada como uma mudança de qualidade tanto pelos produtores quanto consumidores a partir do complexo global agro-food. Como argumenta Goodman (2004:5) “(...) definidos em termos de qualidade, transparência (...)”, bem como localidade, tais redes emergentes estão assinalando uma mudança contrária ao industrializado e convencional setor de alimentos, em direção a um regime re-localizado de alimento e agricultura.

Como salienta Goodman (2004), existe muito espaço de resistência, diversidade e possibilidade, que permite o desenvolvimento de estratégias alternativas àquelas perseguidas no sistema agro-food convencional como práticas ecológicas de produção e relações de confiança e tradição.

Seguindo a discussão apresentada anteriormente, que aponta para a composição dos sistemas produção da banana no Litoral Norte, desmembrado em dois grandes grupos, pode-se dizer, segundo Murdoch e Miele (1999), que o setor contemporâneo de alimentos está se bifurcando em duas "zonas" principais de produção: de um lado o agro-food (convencional), ligado a redes globais de alimentos, industrializadas e padronizadas, e de outro as redes alternativas (ecológicas), ligadas a processos de produção especializados e localizados.

Como sugerem Murdoch e Miele (1999), as relações sócio-naturais são diferenciadamente construídas em cada uma das duas áreas de produção mais gerais (convencional e ecológico), é útil identificar como as cadeias ou redes estabelecidas em cada zona de produção constroem relações sociais, econômicas e naturais e que emergem, podendo assim avançar na avaliação de como os sistemas de produção se estabelecem nos dois lados, e como diferentes sistemas de produção podem reconfigurar as relações entre os produtores e o local. 
Murdoch e Miele (1999) afirmam claramente que a globalização garantiu o surgimento de uma variedade de novos padrões ligados ao modelo convencional de produção. Estes novos padrões têm sido dirigidos pelos preceitos de apropriação e substitucionismo, ou seja, pelo alto grau de externalidades e indústrias transnacionais, e reduziram a qualidade a um jogo de interesses estreitos entre a eficiência e o custo. Mas, em contraponto, há também a incidência de conjuntos alternativos de padrões preocupados com a proximidade à natureza. Como salientam Murdoch e Miele (1999) e Murdoch, Marsden e Banks (2000), em oposição às concepções estreitas de qualidade nas cadeias de alimentos industriais, onde a natureza tem sido continuamente "ignorada", um retorno à natureza pode ser evidenciado em novos circuitos de produção de alimentos (re)emergentes.

Os padrões que prevalecem nestas cadeias ou redes “alternativas' são prováveis então de se diferenciar daqueles que governam as cadeias ou redes industriais. Assim, Murdoch e Miele (1999) salientam que é possível especular que estas redes alternativas serão menos orientadas à eficiência e à competitividade, no que se refere ao custo e preço, mas sim irão procurar negociar na base de qualidades ambientais, nutricionais e/ou salutares. Como argumenta Ploeg (2006), a agricultura é sabidamente um processo de coprodução, e o sistema agroindustrial causou uma ruptura em muitas interdependências entre o natural e o social, diminuindo a capacidade de renovação de ambos.

Mais recentemente, tendências significantes emergiram e minaram muitas das pressuposições que ficam por trás da perspectiva de globalização. Murdoch e Miele (1999) enfatizam que, dada a emergência de consumidores que estão cada vez mais conscientes e preocupados com a qualidade do alimento, o que deriva não somente das questões de gosto/paladar, mas talvez das questões de saúde e segurança, há uma tendência por parte de muitos mercados consumidores em retornar aos alimentos "locais" e "naturais", na esperança de que estes envolvam valor ecológico e valores tradicionais que estão embeddedness (imersos) na constituição das relações sociais que dão margem as redes face-to-face.

Murdoch e Miele (2004) salientam que a variedade e a qualidade natural são critérios do sistema alternativo de alimentos, e que os sistemas de redes alternativas de produção emergem da crise do setor convencional.

Os autores explicam a natureza variada dos critérios de qualidade no setor de alimentos alternativos, citando a crise multifacetada do setor convencional. Mais especificamente, eles argumentam que os movimentos slow food (alimentação sem pressa) 
responde à crise de confiança no setor alimentício; a Soil Association (associação do solo) enfatiza os problemas ambientais que derivam do setor convencional promovendo "melhores práticas orgânicas"; e o Fair Trade (comércio justo) visa reconectar produtores e consumidores, a fim de retornar maior valor ao local de produção.

Marsden et al. (2000) enfatizam que, em contraste com as cadeias convencionais, as redes de alimentos alternativos reconfiguraram as construções naturais, de qualidade, regionais e de valor associadas com a produção de alimentos e mostram ganhos positivos de valor-agregado em termos de receitas agrícolas. Tudo isso, talvez, por terem demonstrado considerável variação de como operam a produção e a comercialização em cadeias curtas (face-to-face) de venda de alimentos.

Alier (1998) ressalta que os impactos ambientais causados pela invasão generalizada das cadeias convencionais, a expansão econômica e o consumo excessivo de alimentos padronizados ocasionam, sobretudo, prejuízos ecológicos e sociais, salientado que, atualmente, toma-se cuidado com os efeitos ambientais da agricultura moderna (contaminação dos alimentos e da água, destruição ou abandono de recursos genéticos, e uso de energias esgotáveis dos combustíveis fósseis). Porém, chama atenção ao fato de que esses efeitos não são medidos pelo mercado e, por isso, os economistas lhes dão o nome de externalidades, ou seja, efeitos externos ao mercado. Por este motivo, Alier (1998) sugere ainda que se duvide do fato de a agricultura moderna ser realmente produtiva, pois nela só são medidos os aumentos mensuráveis de produtividade (por hectare ou ainda por hora de trabalho).

A especialização excessiva, a dependência em relação a insumos, a fraca integração entre os diferentes sistemas, a perda das variedades localmente adaptadas, a erosão do conhecimento referente ao manejo da biodiversidade local, a degradação da qualidade do solo e da água e a crescente desvalorização dos agricultores pelo seu "lugar" foi o que gerou um profundo descolamento das atividades agrícolas em relação aos ecossistemas naturais na Microrregião do Litoral Norte.

\section{A EMERGÊNCIA DA AGRICULTURA ECOLÓGICA À LUZ DAS REDES ALTERNATIVAS DE PRODUÇÃO E DA CRISE DO MODELO CONVENCIONAL}

O estabelecimento de sistemas ditos alternativos de provisão de alimento que caem fora do modelo convencional de agricultura, emerge por muitas razões e dimensões 
diferentes de preocupação, tal como questões de segurança alimentar, assim como as externalidades sociais e ambientais associadas com o modelo convencional de produção.

Mas, fundamentalmente, como argumentam Sonnino e Marsden (2006), o estabelecimento de um circuito curto de comercialização (face-to-face), na cadeia alternativa esta fundado basicamente pelo desenvolvimento de novas relações entre os produtores e consumidores. Neste sentido, uma característica chave das novas redes alimentares é sua capacidade de re-socializar ou re-espacializar alimento (produção), pela identificação de origem (local), mas também pelas relações de confiança estabelecidas entre os produtores e consumidores. Estas relações, na maioria das vezes são definidas pelo sentido de "lugar", como pertencimento e identidade. Desenhando uma nova imagem da propriedade ou região, tanto para consumidores como para produtores. Assim, este local, passa a ser uma fonte de qualidade definida pela confiança.

Com a emergência destas redes alimentares alternativas, Murdoch e Miele (1999) enfatizam que o setor contemporâneo de alimento está bifurcando de forma crescente em duas zonas principais de produção, uma padronizada, especializada em processos de produção respondendo a padrões econômicos de eficiência e competitividade, por um lado. E localizados, especializados e complexos com processos de produção alternativos, por outro. Em que a comercialização se estabelece a partir das qualidades ambientais, nutricionais ou de saúde, pela distinção de sua origem (local). Como argumentam Murdoch e Miele (1999), os alimentos que carregam traços claros de clean e green do ambiente no qual são produzidos tornam-se cobiçados objetos de consumo para seus adeptos, tanto por serem produtos diferenciados quanto pela proximidade com a natureza

De acordo com Sonnino e Marsden (2006), na busca pelo entendimento da alternatividade dos sistemas de alimentos emergentes, um número de cientistas se focou no relacionamento forçado entre estas duas zonas de produção, argumentando que contra a lógica da volumosa produção de commodity, redes alternativas de alimento redistribuem valor sobre a cadeia produtiva, reunindo mais uma vez a confiança entre produtores e consumidores e articulando novas formas de associação política e governança de mercado.

Desta forma, Murdoch e Miele (1999) explicam a emergência de redes alimentares alternativas e a variada natureza do critério de qualidade no setor alternativo se referindo a crise multifacetada do setor convencional. Visto que, em estudos de $\operatorname{casos}^{5}$ realizados por Murdoch e Miele (1999) na Itália, o que transpareceu foi à extrema complexidade de

\footnotetext{
${ }^{5}$ Para maiores esclarecimentos ver: Murdoch, J.; Miele, M. Back to nature: changing worlds of production in food sector. Sociologia Ruralis, 39(4): 465-483, 1999.
} 
apropriações das relações destas redes alternativas e convencionais.

\section{FERRAMENTAS METODOLÓGICAS}

Realizou-se uma pesquisa bibliográfica na busca de uma melhor compreensão das categorias teóricas propostas: a abordagem sistêmica focada ao rural, embeddedness voltado ao estudo dos espaços rurais. E, como fonte de informação complementar, para entender e definir as tipologias dos sistemas e as suas performances, foram utilizados dados secundários coletados em Wives $(2008)^{6}$. Dentro desse contexto, de 2006 a inicio de janeiro de 2007, foi realizada uma pesquisa exploratória com informantes-chave da região, onde foram aplicados questionários com perguntas abertas cujo objetivo consistiu em definir uma tipologia de seus sistemas de produção. Como resultado, seis sistemas de produção foram identificados, nos quais, no período entre janeiro e maio de 2007, foram aplicados 17 questionários, com perguntas abertas e fechadas, de forma não aleatória, sendo em média de três para cada tipo de sistema.

Tais questionários envolveram questões que foram empregadas para definir o funcionamento e as performances dos sistemas de produção, bem como questões relacionadas com as percepções, idade, número de membros da família, técnicas de manejo, acesso à informação e à assessoria técnica.

Com base nas questões de percepção, buscou-se identificar algumas variáveis que seriam úteis na tentativa, de verificar valores e crenças imersas nas relações sociais. Questões estas, por sua vez, que aliadas aos resultados das performances dos sistemas, foram analisadas a partir dos conceitos de embeddedness e re-localização para ajudar a explicar a organização dos sistemas de produção da banana e as suas dinâmicas espaciais no Litoral Norte.

\section{INDICADORES DE DESEMPENHO AGROECONÔMICOS EMPREGADOS NA AVALIAÇÃO DOS SISTEMAS DE PRODUÇÃO}

Dufumier (1996) descreveu as seguintes medidas ou indicadores de desempenho agroeconômico, os quais foram adaptados a este estudo:

\footnotetext{
${ }^{6}$ Para maiores detalhes sobre o trabalho realizado, e para compreender melhor a metodologia utilizada na definição dos referidos sistemas de produção, consultar Wives (2008).
} 
- Superfície Agrícola Útil (SAU) - mede a área (em hectares) que é efetivamente cultivada pelo produtor. Considera-se área ocupada pelas atividades de produção vegetal e animal. Não serão consideradas as áreas de preservação e não cultivadas, além das áreas não exploradas (reflorestamento, área ocupada pelas construções, pomares e hortas domésticas). Para aumentar a precisão das medições, as áreas destinadas exclusivamente ao cultivo de banana tiveram sua determinação por meio de medições com auxilio do Sistema de Posicionamento Global (GPS).

- Unidade de Trabalho Homem (UTH) - Mensura a quantidade de tempo trabalhada por unidade de mão-de-obra. Utiliza o valor de 300 dias homem ou 2.400 horas anuais de trabalho. Como referência, se estabeleceu o valor 1 para o homem (trabalhador) com idade entre 16 a 60 anos que trabalha em tempo integral na atividade agrícola durante esse período ou tempo, 0,8 para a mulher com idade de 16 a 60 anos que trabalha em tempo integral, e 0,5 para as crianças e adolescentes com idade inferior a 16 anos e idosos com idade superior a 60 anos.

- Produção Bruta (PB) - Representa o valor da produção em Reais gerada durante o ano, exclusivamente pela unidade de produção. $\mathrm{O}$ valor dos seguintes produtos e serviços finais compõe o PB: a produção vendida, consumida, transformada e estocada pela família; a produção destinada ao pagamento de serviços de terceiros; a variação do rebanho animal; a remuneração de serviços prestados para terceiros pela mão-de-obra familiar.

- Consumo Intermediário (CI) - Representa o valor em Reais dos insumos e serviços destinados ao processo de produção, adquiridos de outros agentes econômicos (sementes, fertilizantes, corretivos, fungicidas, energia).

- Renda Agrícola (RA) - Representa a parte do valor agregado que fica com o agricultor para remunerar o trabalho familiar e aumentar seu patrimônio. O que não for utilizado para a sobrevivência, poderá ser reinvestido na unidade de produção na compra de terras, ampliação das instalações, compra de novos equipamentos ou no conforto e bem estar da família (compra de carro, televisor, parabólica, aparelhos domésticos).

- KI - Capital: este indicador é composto pelo somatório do valor atual do patrimônio colocado à disposição da produção (terra, máquinas, equipamento, instalações, benfeitorias, efetivo médio dos rebanhos bovinos, ovinos e eqüinos, e 
dos animais domésticos), do consumo intermediário (CI).

- TL - a taxa de lucro é obtida a partir da seguinte equação: (TL=RA/KI).

\section{CATEGORIAS ANALÍTICAS}

\section{ABORDAGEM SISTÊMICA APLICADA AO ESTUDO DO RURAL}

Como salientam Mazoyer e Roudart (2001), a abordagem de sistemas agrários permite apreender toda a complexidade que é apresentada ao se buscar o entendimento de realidades que nada mais são do que sistemas de objetos abstratos que podem ser cuidadosamente elaborados para constituir um verdadeiro objeto concebido. De acordo com Mazoyer e Roudart:

[...] a teoria dos sistemas agrários é um instrumento intelectual que nos permite apreender a complexidade de cada forma de agricultura e nos darmos conta, a traços largos, das transformações históricas e da diferenciação geográfica das agriculturas humanas. (MAZOYER E ROUDART, 2001:39).

Como argumentam Mazoyer e Roudart (2001), um sistema é formado por um conjunto de elementos que possuem variáveis e características que têm relações entre si e também com o ambiente. O pensamento sistêmico leva em conta categorias como o espaço (a situação como estão postas as coisas no ambiente), a paisagem (como sendo uma construção pessoal do espaço concreto) e o território (espaço que possui uma gestão social). Eles consideram, assim, um sistema como sendo um objeto complexo que troca entre suas partes energia, matéria e informações. A teoria de sistemas agrários tenta apreender a complexidade do sistema em estudo.

Desta forma, Mazoyer e Roudart (2001) definem que um sistema agrário é um modo de exploração do meio historicamente constituído, um sistema de forças de produção, um sistema técnico adaptado às condições bioclimáticas de um espaço determinado, que responde às condições e às determinações sociais do momento.

\section{SISTEMA DE PRODUÇÃO}

Considerando a escala do estabelecimento rural, o sistema de produção pode ser definido como uma combinação, no tempo e no espaço, dos recursos disponíveis, com a finalidade de obter produções vegetais e animais. Pode também ser entendido como uma combinação coerente de vários subsistemas produtivos. A análise dos sistemas de 
produção na esfera do estabelecimento rural incide em argüir seus dados constitutivos e, especialmente, as relações que se estabelecem entre eles. Como argumenta Dufumier (1996), é de fundamental importância identificar a coerência e a complexidade interna dos sistemas de produção, bem como as relações de sinergia ou de complementaridade relacionadas à utilização dos recursos.

Deffontaines (1973) argumenta que, no meio rural, de forma geral tem se utilizado as teorias tradicionais das organizações que consideram as unidades de produção como um sistema fechado, que desenvolvem suas explorações baseadas numa mesma lógica (a do sistema dominante), estando aptas a receber tecnologias desenvolvidas em outras realidades. Os sistemas de produção, segundo Dufumier (1996), são por si só muito complexos, porque admitem incluir um grande número de elementos vivos que interagem entre si e com o ambiente, e, também, porque respondem à influência de fatores sócioeconômicos. Seu funcionamento, conforme Deffontaines (1973), deve ser atribuído à natureza das relações sociais estabelecidas em volta de sua exploração.

\section{ENTENDENDO EMBEDDEDNESS COMO UMA FERRAMENTA ANALÍTICA}

Como Murdoch et al. (2000) e Winter (2003b) indicam, a noção de embeddedness tem uma longa linhagem com Granovetter. De acordo com Granovetter:

O conceito de embeddedness esta associado com a "substantivist" escola de antropologia, com um expoente Polanyi (1944; POLANYI, ARENSBERG, e PEARSON 1957) e com as idéias da "moral econômica" advinda da história e da ciência política. (THOMPSON 1971; SCOTT 1976). (GRANOVETTER, 1985:482).

No cerne do conceito de embeddedness está a ênfase situada na necessidade de relações sociais para todas as transações econômicas. Granovetter (1985) enfatiza a importância do papel das relações sociais na geração da confiança necessária para as transações econômicas ocorrerem, quanto maior a confiança menor os custos de transação. Transparecendo, assim, que isso não é meramente uma questão de confiança na qual ela mesma implica em um auto-interesse que não é compatível com a economia clássica e neoclássica.

Portanto, a literatura de embeddedness se concentrou nos componentes sociais da ação econômica (MURDOCH et al., 2000).

O conceito de embeddedness, ganha o elemento espaço, com estudos realizados pela 
Geografia Econômica na medida em que muitos autores buscavam entender como as relações sociais de consumo e produção estão baseadas em relações de confiança entre produtores e consumidores, fato que estaria emergindo do local.

\section{A IMPLICAÇÃO DO PROCESSO DE EMBEDDEDNESS NA ANÁLISE DO ESPAÇO RURAL}

O conceito de embeddedness, como entendem Sonnino e Marsden, Murdoch, Banks e Kirwan, parte da corrente da neo-regionalização (o local-food). Assim, esses autores argumentam que tal conceito pode ser uma importante forma de aprofundar as investigações das relações entre local e alimento, salientando que esta noção é amplamente usada para enfatizar o componente social da ação econômica. Nos estudos de local-food, embeddedness tem demonstrado ser um conceito eficaz para enfatizar a maior defesa do caráter social das redes alimentares alternativas, pois como afirma Polanyi (1980) os mercados são socialmente construídos. Assim este estudo entende que a partir deste conceito pode-se perceber como os atores sociais estão embeddedness (imersos) na construção social dos mercados fundado no local, na proximidade e confiança. Sendo importante para explicar como se dão a relação entre o local e o alimento e como isso pode estar implicado na dinâmica de um determinado espaço. O que tende a ser compreendido por Marsden (2006) como re-localização.

De acordo com Sonnino; Marsden (2006), o embeddedness pode se tornar um verdadeiro conceito explanatório poderoso, como reforça Winter $\left(2003^{\mathrm{a}}\right.$ : 25), "Mas, em verdade, todas as relações de mercado são socialmente imersas em uma variedade de maneiras contrastantes (...)", assim argumentando que, nos estudos de agro-food, também se faz necessário avaliar suas implicações fora do domínio social. Sendo assim, de acordo com o que alguns pesquisadores iniciaram a argumentar, o conceito de embeddedness passa a assumir um significado muito mais amplo no contexto da produção de alimentos, pois inclui também as dimensões econômicas, ambientais, culturais e políticas dos sistemas de produção de alimentos.

Nos estudos realizados por Murdoch et al. (2000), utilizou-se a noção de embeddedness para descrever o inter-relacionamento entre natureza, proveniência e qualidade que diferencia produtos locais de alimento de commodities globalizadas.

Mais recentemente, Kirwan (2004, p. 397) afirma que “(...) a utilização das noções de embeddedness tem tido uma crescente e pertinente utilização (...)", evidenciando as 
tentativas para se esclarecer os atributos da utilização de embeddedness como referência para promover alteração; valorização potencialidades do "local", "localidade"; e bem como sua apropriação comercial. Para tanto, Kirwan (2004) utiliza uma abordagem mais orientada ao ator. Desta forma, evidencia-se que há muitas possibilidades de operacionalizar os conceitos acima referidos, entretanto deixando clara a sua grande importância analítica.

\section{ANÁlise DOS SISTEMAS DE PRODUÇÃO DA BANANA NA MICRORREGIÃO NORTE DO RIO GRANDE DO SUL}

A seguir serão analisadas as performances dos indicadores de desempenho econômicos empregados com a intenção de caracterizar os sistemas de produção identificados por este estudo. Assim, a Figura 1 ilustra a relação entre os sistemas de produção e os sistemas de cultivo.

Inicialmente tal discussão parte dos diferentes índices de desempenho econômico obtidos pelos sistemas de produção estudados, considerando a relação da quantidade de recursos financeiros e disponibilidade dos fatores de produção, tais como quantidade, qualidade da terra e mão-de-obra, e do estabelecimento de prazos, ou seja, do tempo que define as épocas das atividades, pagamentos, recebimento e das operações agrícolas.

Sistema de Produção

$$
\text { SP1: Convencional empresarial }
$$
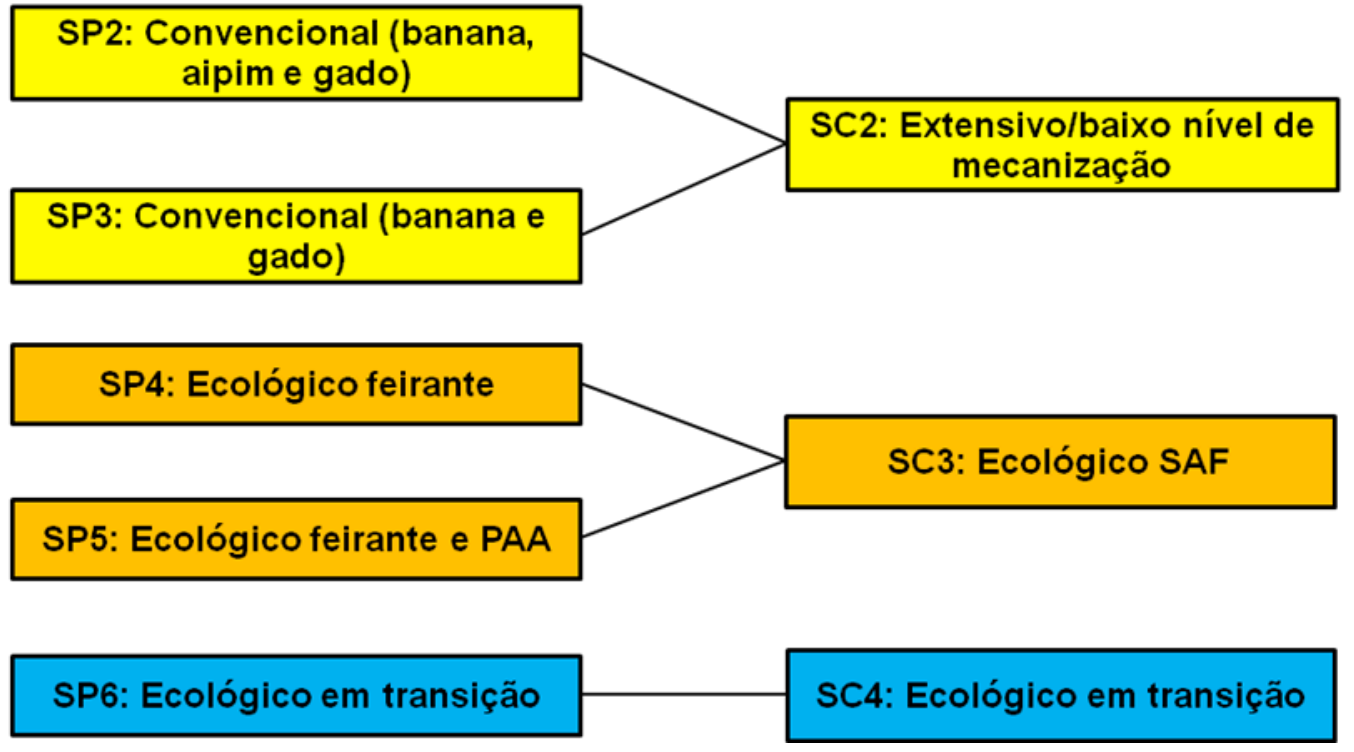
Figura 1. Demonstrativo dos sistemas de produção em relação aos seus respectivos sistemas de cultivo

Percebeu-se, como demonstram as informações contidas em Apêndice, que os sistemas de produção SP4, SP5 e SP6 apresentam dados que indicam uma eficiência técnica/produtiva menor, em termos de escala, do que o sistema convencional SP1. Mas, se comparados aos sistemas convencionais SP2 e SP3, esses apresentam uma maior produtividade média por hectare, além de combinarem de forma mais eficiente a quantidade dos recursos financeiros, fatores de produção e a articulação com os canais de comercialização. Os sistemas de produção SP4, SP5 realizam a comercialização da sua produção por meio de cadeias curtas, vendendo diretamente ao consumidor em feiras livres semanais, localizadas em cidades como Porto Alegre, Caxias do Sul, Canoas e Torres, ou para programas do Governo Federal como o Programa de Aquisição de Alimentos (PAA).

$\mathrm{Na}$ Figura 2 apresentam-se os dados referentes à renda agrícola média por sistema de produção. Nos sistemas SP2 e SP3 pode-se observar um desempenho similar aos dos sistemas de base ecológica SP4, SP5 e SP6. Em relação a este indicador, apenas o sistema SP1 atinge valores que destoam dos demais.

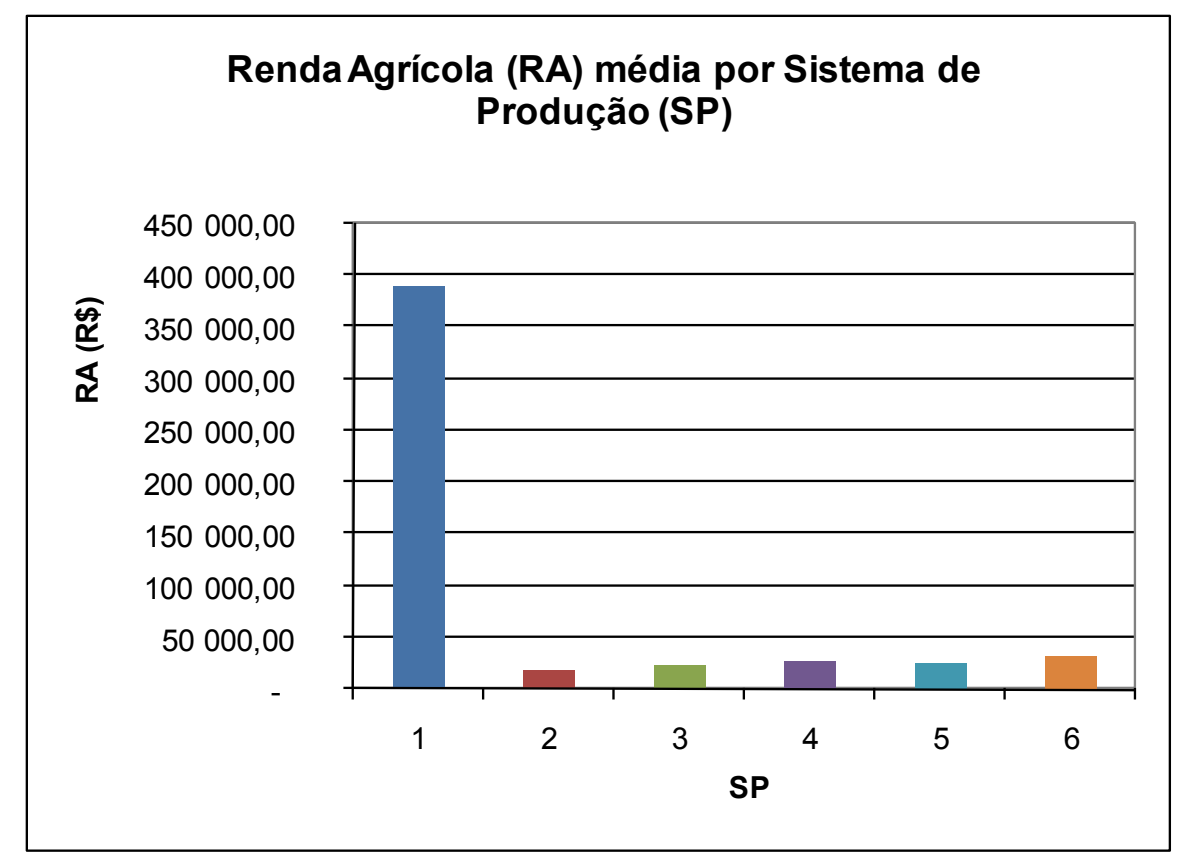

Figura 2. Gráfico da renda agrícola (RA) média por sistemas de produção 


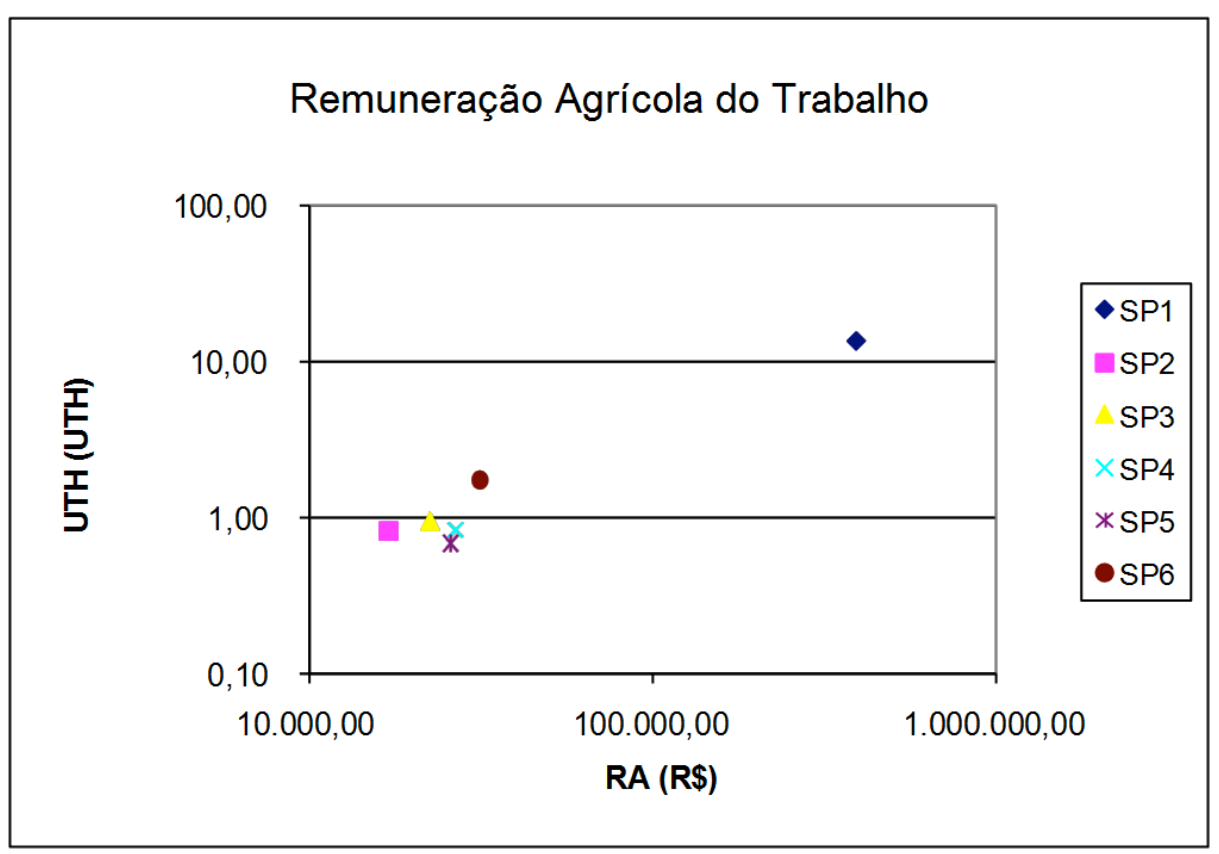

Figura 3. Gráfico da remuneração agrícola do trabalho (escala logarítmica)

$\mathrm{Na}$ Figura 3 apresenta-se um gráfico de renda bruta por unidade de área (RA/UTH). Este gráfico agrega dados que fundamentam a discussão iniciada acima, onde se pode perceber que os sistemas de base ecológica SP4 e SP5 são mais eficientes que SP2 e SP3, sem contar o fato de que o tamanho da SAU, neste estudo, não apresenta uma relação direta com o valor da renda. É importante salientar, que mesmo utilizando áreas úteis menores, os sistemas de produção SP4 e SP5 obtêm um desempenho mais elevado de RA. Já o sistema SP6 apresenta um valor de RA mais elevado que os demais sistemas de base ecológica, sendo ainda o sistema com o maior valor de UHT.

A Figura 4 demonstra um gráfico contendo a remuneração (RA) e a remuneração por unidade de área agrícola útil (SAU). 


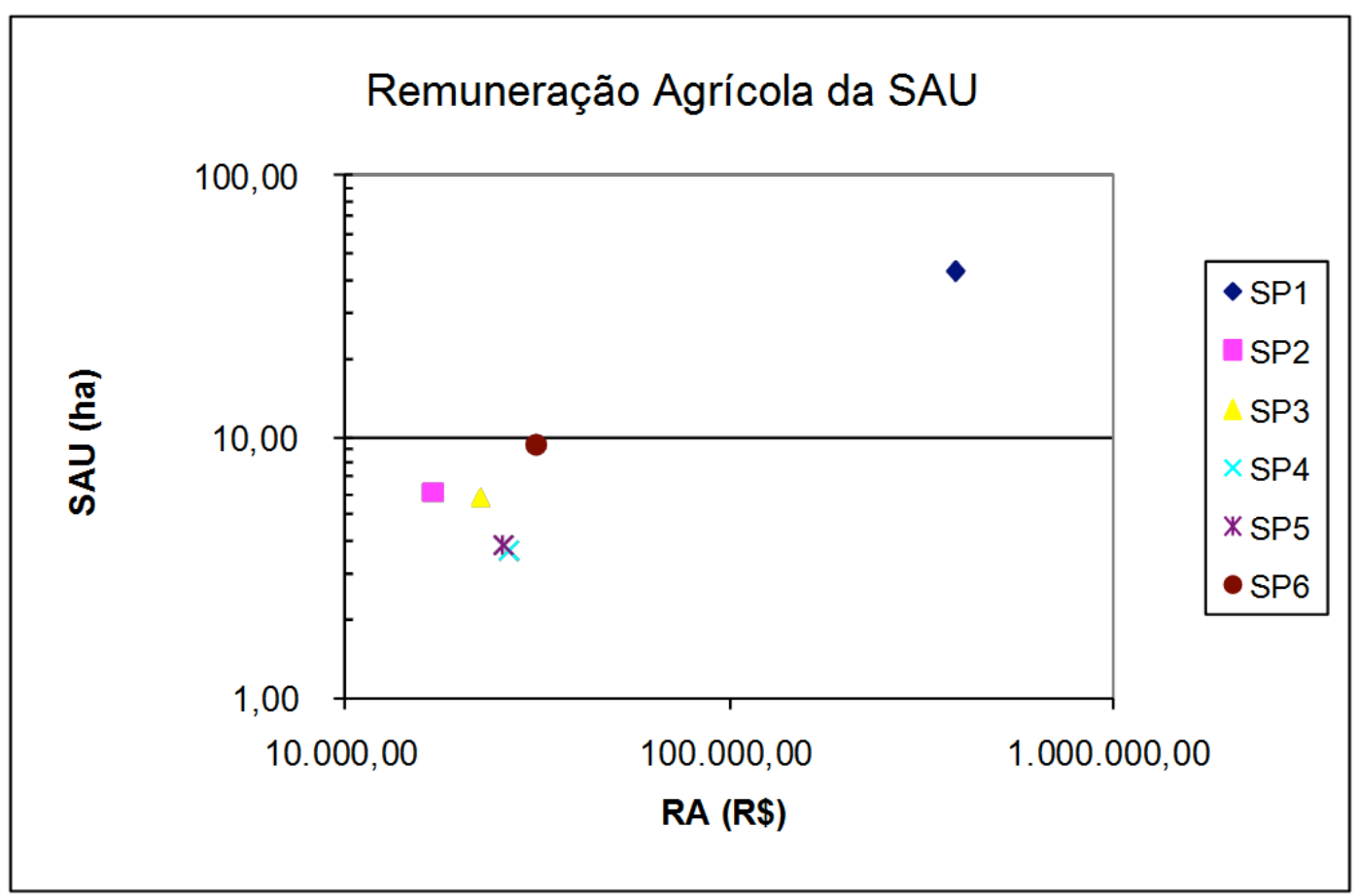

Figura 4. Gráfico da remuneração agrícola da superfície de área útil (em escala logarítmica)

Os dois gráficos anteriores demonstram que os sistemas de base ecológica SP4, SP5 e SP6 são os que apresentam melhor remuneração, seja por superfície agrícola útil (SAU), seja por unidade de trabalho homem (UTH).

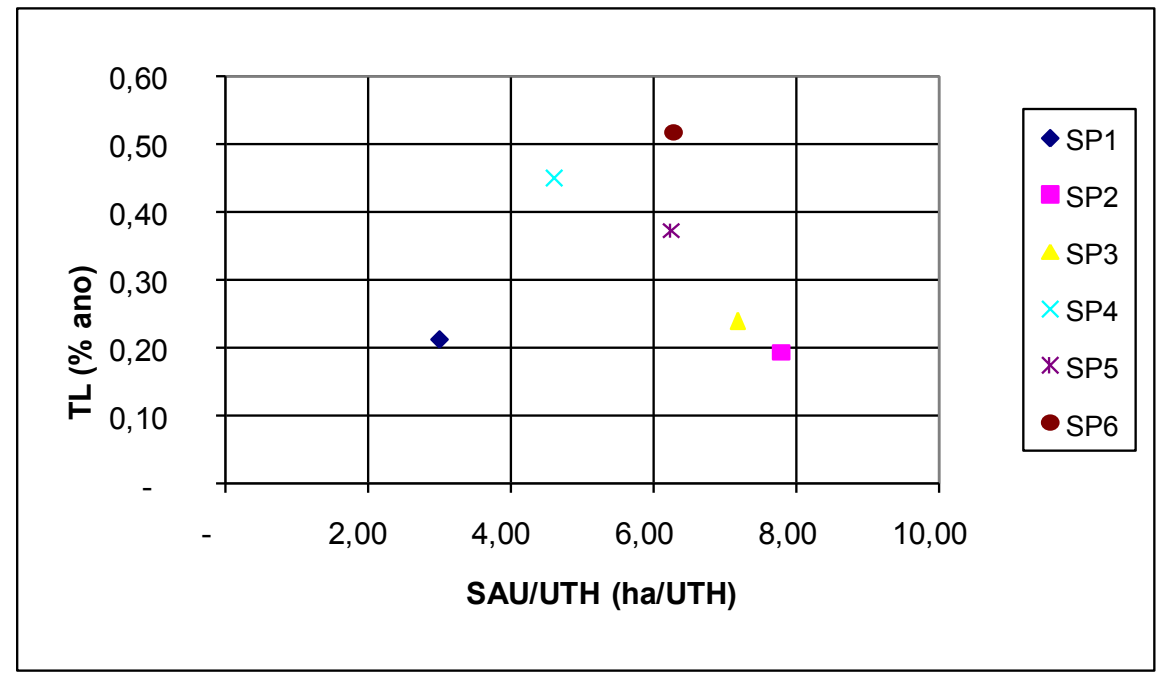

Figura 5. Gráfico da taxa de lucro (TL)

A taxa de lucro (TL), apresentada no gráfico da Figura 5, demonstra uma média total, dos sistemas de produção convencionais SP1, SP2 e SP3 de 21,6\%. Nos sistemas de produção de base ecológica este indicador apresenta valor de 44,6\%, muito maior que os sistemas de produção convencionais. Este fato torna ainda mais importante realçar que a 
disponibilidade de superfície útil por unidade de trabalho homem (UTH) nos sistemas de produção de base ecológica é menor. Ou seja, os dados apresentados nas Figuras 3 e 4 demonstram que, na população estudada, a intensidade do trabalho e o SAU não têm uma relação com a taxa de lucro (TL) obtida pelos sistemas de produção de base ecológica SP4, SP5 e SP6, isso se deve fundamentalmente pela forma de comercialização em cadeias curtas e pelo manejo que aproveita melhor as potencialidades ambientais.

Os valores referentes ao gráfico da Figura 5 refletem as dificuldades dos sistemas de produção convencionais SP2 e SP3, visto que estes auferem pior desempenho econômico. Contrariamente, percebeu-se que o sistema de produção convencional SP1 é o sistema que apresenta indicadores econômicos com desempenho um pouco melhores se comparados aos demais sistemas de produção convencionais. É relevante realçar que mesmo buscando diminuir o uso de insumos químicos (empregando manejos e tecnologias mais modernas) este ainda é o sistema que gera o impacto ambiental ${ }^{7}$ mais elevado, dentre todos deste estudo, pelo uso intensivo de insumos de origem fóssil.

Os resultados das discussões acima possibilitam evidenciar as proposições de Dufumier (1996), Deffontaines (1973) e Marsden et al. (2000), provavelmente por verificar a capacidade dos produtores em construir seus sistemas de produção, não ignorando os seus objetivos econômicos, o que, por sua vez, torna mais simples de entender as diferentes organizações se comparando os sistemas de produção convencional e de base ecológica.

Em relação ao funcionamento técnico, foi possível observar o contraste existente entre os sistemas convencionais e os de base ecológica, principalmente no que diz respeito à forma como estes se relacionam com a paisagem, com a qualidade, com os valores regionais. Mesmo assim, ou por causa disto, os sistemas de base ecológica mostram ganhos positivos em termos de receitas agrícolas. Isto se dá, provavelmente, pela forma como estes agricultores organizam seu sistema de produção e cultivo, por atuarem com um consumo intermediário menor e pela forma como realizam a comercialização em cadeias curtas.

O cultivo da banana na Microrregião Litoral Norte do RS é praticado em uma área situada nas vertentes da Serra Geral, o que implica dizer que o terreno é acidentado. Em geral, este cultivo ocupa uma faixa altimétrica de trezentos metros, condições estas que limitam o uso de equipamentos de tração de grande porte.

\footnotetext{
${ }^{7}$ Este custo, por sua vez, não foi levado em consideração na elaboração dos cálculos de nenhum sistema estudado.
} 
Nestas condições paisagísticas evidenciam-se indicativos que demonstram por que os sistemas de base ecológica se relacionam de forma mais harmoniosa com as potencialidades deste espaço.

Os sistemas convencionais de cultivo aplicam como uma forma de manejo a limpeza total das áreas dos bananais, o que implica numa cobertura nula, ou muito baixa, do solo. Logo, estes bananais estão mais suscetíveis a processos erosivos e a perda de fertilidade. Os sistemas de cultivo de base ecológica aplicam técnicas de manejo que priorizam a cobertura do solo por meio de roçadas (de controle) e da adubação verde, o que contribui para a ampliação e manutenção da fertilidade do solo, diminuindo a incidência de processos erosivos.

O manejo utilizado pelos sistemas de cultivo de base ecológica, na maioria dos casos, busca uma sinergia com a vegetação nativa em prol da espécie cultivada, além da sinergia com outros cultivos que compõem o sistema de produção (milho, feijão, aipim, hortaliças e frutíferas), o que não se observa nos sistemas de cultivo convencionais, onde a única espécie de vegetação tolerada na área de cultivo é a banana.

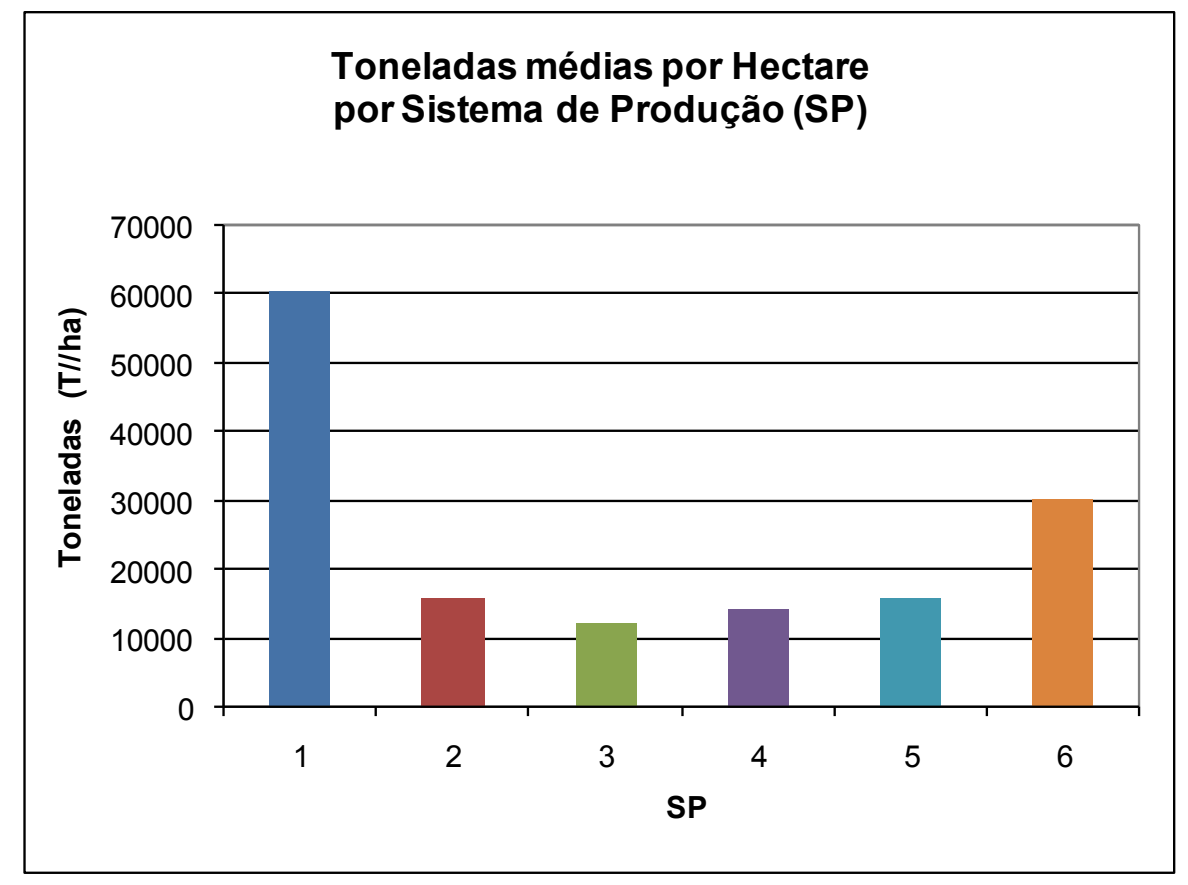

Figura 6. Gráfico da média de toneladas por hectare, por sistema de produção

Finalmente, a partir dos dados apresentados neste trabalho, é possível afirmar que os sistemas de cultivo de base ecológica relacionam de forma mais eficiente as interações existentes entre os diferentes elementos, como paisagem, diversidade vegetal e mão-deobra, os quais em determinada medida determinam seu rendimento. Estes sistemas 
apresentam uma produtividade média mais elevada, se comparando aos sistemas convencionais (exceto o sistema de produção SP1), como demonstra a Figura 6.

\section{O PROCESSO DE RE-LOCALIZAÇÃO NO LITORAL NORTE DO RS}

No caso do cultivo da banana praticado na Microrregião do Litoral Norte, como demonstra Wives (2008), a produção está pautada, por um lado, em uma agricultura dependente de insumos e dos mercados. Tal agricultura, em muitos casos, deixa transparecer a dificuldade que os agricultores ligados ao sistema de produção convencional têm, pois não atingem as articulações para operar nesse modelo produtivo de escala. Por outro lado, apresentam-se os sistemas de produção base ecológica, no qual se observa a importância da comercialização, da tradição, confiança, do local e da qualidade como pressupostos fundamentais da ação dos atores. Buscou-se, nesta seção, entender a importância do conceito de embeddedness no processo de re-localização no litoral norte.

Como afirmam Sonnino e Marsden (2006), a re-localização apresenta uma relação espacial que esta embeddedness (imersa) nas redes alternativas de produção de alimentos.

Estas redes alternativas de produção de alimentos apresentam, quanto às relações de produção, a importância da qualidade, estratégias para agregar valor a produção e nichos de desenvolvimento. Em relação à comercialização pauta-se na importância do conhecimento do lugar ou da origem dos produtos, opera comercializando "face-to-face" baseando-se em relações de confiança e eminentemente em cadeias curtas.

Guardando-se as devidas proporções e limites do trabalho aqui apresentado, uma nova contribuição deste estudo consiste na busca por desvelar a importância das percepções dos atores e como o conceito de embeddedness está relacionado com construção das relações destes com o local e os seus sistemas de produção. Suas escolhas se deram de acordo com os objetivos e com as percepções destes agricultores, visto que, em relação à principal motivação para focar sua atividade no cultivo da banana, $67 \%$ dos produtores dos sistemas de base ecológica SP4, SP5 e SP6 escolheram-na por ser uma tradição familiar e da sua ligação com o local. Já no caso dos agricultores dos sistemas convencionais sua inserção no sistema convencional está baseada em variáveis distintas, como trabalho, produção intensiva entre outros, com o intuito de atingir uma maior lucratividade ${ }^{8}$.

\footnotetext{
${ }^{8}$ Para maiores detalhes sobre os valores apresentados, a cerca das percepções dos agricultores dos sistemas de produção estudados, consultar Wives (2008).
} 
Assim, é possível verificar o que Dufumier (1996), Deffontaines (1973), Murdoch et al. (2000) e Kirwan (2004) afirmam: que esses sistemas nascem das relações sociais imersas nestas redes alternativas. As quais estão se reconfigurando dentre as percepções dos agricultores no decorrer do tempo do espaço. Para que os atores, ao nível do indivíduo, atinjam seus objetivos pessoais, sejam eles de caráter econômico, cultural, subjetivo, físico ou produtivo. Assim, embeddedness como referência analítica proporcionou evidenciar as alterações do valor, que neste estudo refletiu a valorização das potencialidades do "local" e da "localidade", pelos agricultores dos sistemas de base ecológica.

Isto significa afirmar que este alimento não é apenas considerado um produto, pois carrega implícita a significação da tradição, do local, da qualidade e relações de confiança.

Para estes agricultores que operam vinculados a uma base ecológica de produção cabe argumentar que, não somente o próprio alimento representa diferentes convenções de qualidade, mas, também, o modo da organização social e dos canais de comercialização foi totalmente re-organizado, passando, no caso da comercialização, a vender diretamente para o consumidor.

Confirmaram-se os argumentos de Marsden (2003), os quais ressaltam que a produção e as cadeias de abastecimento são mais variáveis e dependentes do contexto onde o valor é aprendido, e o uso de identificação especial para a produção de alimentos tem uma importante dimensão, denotando novas formas de regulação de qualidade, como as certificações de qualidade associadas com produção ecológica.

Este estudo evidenciou que numa produção focando alimentos ecológicos, se apresenta um caminho para reversão do processo, dos últimos anos, de intensificação e especialização do processo de externalização das atividades dos sistemas produtivos. Nos sistemas de produção de base ecológica estão se criando novos mercados, valorizando a produção dos alimentos regionais, locais, tradicionais do lugar.

Como salienta Marsden (2003), tais alterações representam a mais profunda mudança nos padrões de governança, mais que a emergência de novos produtos, criando mercados independentes. Desta forma instituem-se novas formas de relações sociais e associações, com padrões alternativos de qualidade, que no caso especifico deste estudo, favorecendo o ecológico, o tradicional e o local. Desta forma foi possível verificar que o desenvolvimento desses tipos alternativos de redes alimentares está configurando-se na 
Microrregião do Litoral Norte por meio da resignificação do lugar ou do espaço.

\section{CONCLUSÃO}

As análises realizadas neste trabalho buscam por um lado demonstrar as performances dos sistemas de produção da banana na microrregião do Litoral Norte do RS. E por outro lado mostrar como esta se dando processo de re-localização do alimento (banana) neste espaço. Acerca dos sistemas de produção e de cultivo pode-se afirmar que, de forma geral, os indicadores técnicos e econômicos demonstram que os sistemas de produção de base ecológica são mais eficientes, quando comparados aos sistemas de produção convencionais SP2 e SP3. Sendo assim, em larga medida, é possível desconstruir uma idéia há muito adotada pelo senso comum de que os sistemas de produção ecológicos são menos rentáveis e menos produtivos do que os sistemas de produção convencionais.

A eficiência, em termos de quantidades produzidas, de SP4, SP5 e SP6, se dá pela sinergia mais forte ao relacionar critérios de paisagem, espécies vegetais e mão-de-obra de forma mais apropriadas ao seu sistema de cultivo. Os indicadores econômicos demonstram que a performance dos sistemas de produção de base ecológica atingem uma eficiência econômica semelhante e até um pouco mais elevada do que a dos sistemas de produção convencionais SP2 e SP3.

Os resultados econômicos dos sistemas de produção de base ecológica levantam indícios de que sua viabilidade está atrelada intimamente à venda de produtos em mercados diferenciados, à eficiência produtiva e ao seu custo de produção. Os resultados obtidos neste trabalho sugerem que a maioria dos estabelecimentos convencionais que se dedicam ao cultivo da banana apresenta desempenhos menores, em muito, pelo fato de terem seu potencial seja de investimento, produtivo ou de qualidade atrelado ao tipo de comercialização, à falta de conhecimentos técnicos produtivos e à falta de uma melhor articulação com a paisagem.

Outra contribuição proporcionada por este estudo, mesmo que tímida, assenta-se nas observações relacionadas às percepções dos agricultores ao organizarem seus sistemas de produções e cultivo, o que pode explicar as diferenças constitutivas fundamentais entre eles. Tal fato pode ser verificado nos sistemas ecológicos SP4 e SP5, cuja principal motivação esta embeddedness (imerso) no local e na tradição familiar. Já a inserção dos agricultores nos sistemas de produção convencionais está baseada em motivações distintas, como trabalho, produção intensiva, lucro entre outros. Esses pressupostos conduzem esses 
agricultores de forma não intencional a dar um novo sentido ao lugar, o qual está associado ao alimento lá produzido. Criando uma nova imagem da propriedade ou região, como se ela fosse uma fonte de qualidade e tradição, assim re-localizando o alimento.

Este estudo evidenciou que os sistemas de produção e cultivo de base ecológica estão mais diretamente ligados às práticas locais, à cultura, à paisagem e aos recursos. Assim, para entender a importância central do processo de re-localização, cabe a sugestão da compreensão da interpretação do desenvolvimento do agro-food juntamente com o entendimento da natureza das dinâmicas referentes ao embeddedness de espaços competitivos pelas redes alternativas e convencionais. Isso, no espaço da Microrregião do Litoral Norte do RS, começa a revelar a evolução de novas micro-geografias (remodelação do espaço) do espaço rural. O estudo demonstra ainda que o desenvolvimento da agricultura de base ecológica gerou uma remodelação do espaço rural, criando nichos e novas estruturas organizacionais do espaço. Como redes que concorrem com o sistema mais produtivista e estandardizado estabelecido pelo setor convencional.

É relevante demonstrar que a re-localização ainda é objeto de debates, no quais suas bases conceituais estão sendo discutidas, não se apresentando de forma muito clara na literatura da nova Geografia Econômica. Desta forma é importante retomar e valorizar o espaço rural e, desta maneira, argumentar em prol de seu potencial importante no processo de elucidação de novas formas de desenvolvimento rural.

No caso dos agricultores de base ecológica da Microrregião do Litoral Norte, a alternativa aponta para a agricultura sustentável, operando em curtas cadeias produtivas, em pequenos estabelecimentos, o que leva também a um aprofundamento da relação do agricultor com o lugar, e reconfigura totalmente as potencialidades dos recursos de determinados espaços rurais. Desta forma, este processo unifica os agricultores e o alimento por suas singularidades advindas do embeddedness e potencialidades naturais de tal espaço. Como resultado dessa alteração tão profunda dos modos de produção do alimento e significação do lugar, da localidade, pode-se determinar a re-localização. Um aspecto da re-localização que é percebido por esta analise é a reativação do espaço rural tal como um agente ativo na configuração de espaços competitivos entre os setores convencional e ecológico na microrregião do Litoral Norte do RS.

Entretanto, para que seja possível obter uma melhor compreensão, bem como maiores detalhes e fidedignidade em relação a essas inferências, faz-se pertinente que essa questão seja mais bem analisada e discutida em trabalhos futuros. 


\section{REFERÊNCIAS}

ALIER, J. M. Da economia ecológica ao ecologismo popular. Blumenau, SC: FURB, 1998.

DEFFONTAINES, J. P. Analyse du paysage et étude regionale des systèmes de production agricole. Economie Rurale, Paris, v. 98, n. 1, p.3-13, oct./dec. 1973.

DUFUMIER, M. Les projets de développement agricole: manual d'expertise. Paris: Karthala et CTA, 1996. 354 p.

FEE, Fundação de economia e estatística, FEE dados. Disponível em: $<$ http://www.fee.rs.gov.br/feedados/consulta/menu_consultas.asp?tp_Pesquisa=var_Anu al>. Acesso em: 27. jan. 2007.

GONÇALVES, A. Agricultura e floresta: antagonismo ou integração? In:

SEMINÁRIO ESTADUAL, 1 ; SEMINÁRIO REGIONAL DE REFLORESTAMENTO E RECUPERAÇÃO AMBIENTAL, 4., 2000, Ijuí. Anais... Ijuí: UNIJUÍ, 2000.

GOODMAN, D. Rural Europe redux? Reflections on alternative agro-food networks and paradigm change. Sociologia Ruralis, v. 44, n. 1, p.3-16. 2004.

GRANOVETTER, M. Economic action and social structure: the problem of embeddedness. American Journal of Sociology, v. 91, n. 1, p. 481-510. 1985.

HINRICHS, C. C. Embeddedness and local food system: notes on two types of direct agricultural market. Journal or Rural Studies, v. 16, n. 3, p. 295-303. 2000.

HINRICHS, C. C. The practice and politics of food system localization. Journal of Rural Studies, v.19, n.1, p. 33-45. 2003.

KIRWAN, J. Alternative strategies in the UK agro-food system: interrogating the alterity of farmers' markets. Sociologia Ruralis, v. 44, n. 4, p. 512-528. 2004.

MARSDEN, T. The Condition of rural Sustentability. Assen, The Netherlands: Royal Van Gorcum, 2003.

MARSDEN, T.; BANKS, J.; BRISTOW, G. Food supply chain approaches: exploring their role in rural development. Sociologia Ruralis, v. 40, n. 4, p. 424-438. 2000.

MAZOYER, M. ; ROUDART, L. História das agriculturas do mundo: do neolítico à crise contemporânea. Lisboa: Instituto Piaget, 2001. 520 p. 
MURDOCH, J,; MIELE, M. A new aesthetic of food? Relational reflexivity in 'alternative' food movement. In: HARVEY, M.; MCMEEKIN, M.; WARDE, A. (eds) Qualities of Food. Manchester: Manchester University. 2004. p. 156-175.

MURDOCH, J.; MARSDEN, T.; BANKS, J. Quality, Nature and Embeddedness: some theoretical considerations in context of the food sector. Economic Geography, v. 76, n. 2, p. 107-125. 2000.

MURDOCH, J.; MIELE, M. 'Back to nature': changing 'worldss o production' in the food sector. Sociologia Ruralis, v. 39, n. 4, p. 465-483. 1999.

POLANYI, K. A grande transformação: as origens da nossa época. RJ. Ed. Campus, 1980

PLOEG, J. D. van Der. Agricultural production in crisis. In: CLOKE, P.; MARSDEN, T.; MOONEY, P. (eds.). Handbooek Studies, 2006. p. 258-278.

SONNINO, R.; MARSDEN, T. Beyond the divide: rethinking relationships between alternative and conventional food Networks in Europe. Journal of Economic Geogrphy, v. 6, n. 1, p. 181-199. 2006,

SOUZA SANTOS, Z; SOUZA, M; CARRIERI, A. A pesquisa em sistemas de produção: uma revisão. Agricultura em São Paulo, São Paulo, v. 41, n. 1, p. 127-139. 1994.

VIVAN, J. L. Saber ecológico e sistemas agroflorestais: um estudo de caso na floresta atlântica do litoral norte do RS, Brasil. 2000. 98 f. Dissertação (Mestrado em Agroecossistemas) - Curso de Pós-graduação em Agroecossistemas, UFSC, Florianópolis, 2000.

WINTER, M. Embeddedness, the new food economy and defensive localismo. Journal of Rural Studies, v. 19, n. 1, p. 23-32. 2003a.

WINTER, M. Geographies of food: agro-food geographies - making reconnections. Human Geography, v. 27, n. 4, p. 505-513. 2003 b.

WIVES, D. G. Funcionamento e performance dos sistemas de produção da banana na Microrregião do Litoral Norte do Rio Grande do Sul. 2008. 164 f. Dissertação (Mestrado em Desenvolvimento Rural) - Curso de Pós-graduação em Desenvolvimento Rural, UFRGS, Porto Alegre, 2008. 


\section{APÊNDICE}

Tabela de índices por Sistema de Produção (médias)

\begin{tabular}{|c|c|c|c|c|c|c|}
\hline Indicador & Média SP1 & Média SP2 & Média SP3 & Média SP4 & Média SP5 & Média SP6 \\
\hline SAU (ha) & 43,00 & 6,12 & 5,83 & 3,67 & 3,83 & 9,33 \\
\hline UTH & 13,59 & 0,82 & 0,94 & 0,84 & 0,69 & 1,77 \\
\hline PB (R\$) & $1.105 .820,00$ & $25.713,33$ & $37.328,00$ & $34.256,67$ & $42.359,50$ & $70.566,17$ \\
\hline CI (R\$) & $463.580,50$ & $6.715,10$ & $10.385,25$ & $5.855,50$ & $9.747,46$ & $19.295,42$ \\
\hline VAL (RS) & $562.217,07$ & $18.180,48$ & $25.308,67$ & $27.339,92$ & $30.453,61$ & $48.837,25$ \\
\hline VAB (RS) & $642.239,50$ & $18.998,23$ & $26.942,75$ & $28.401,17$ & $32.612,04$ & $51.270,75$ \\
\hline DVA (R\$) & $171.868,50$ & $1.223,33$ & $2.855,83$ & 766,00 & $4.672,33$ & $17.491,67$ \\
\hline RA (R\$) & $390.348,57$ & $16.957,15$ & $22.452,84$ & $26.573,92$ & $25.781,27$ & $31.345,59$ \\
\hline RT (R\$) & $1.050 .348,57$ & $18.857,15$ & $26.452,84$ & $26.753,92$ & $29.701,27$ & $46.065,59$ \\
\hline SAU/UTH (ha/UTH ano) & 3,01 & 7,78 & 7,17 & 4,61 & 6,24 & 6,27 \\
\hline VAL/UTH (RS/UTH ano) & $4.998,94$ & $22.395,65$ & $33.667,85$ & $34.677,40$ & $48.634,43$ & $34.180,15$ \\
\hline VAL/SAU (RS/ha ano) & 10589,43 & $3.012,47$ & $4.718,36$ & $8.074,30$ & $8.402,90$ & $6.087,70$ \\
\hline RA/SAU (R\$/ha ano) & $3.988,40$ & $2.688,03$ & $4.027,52$ & $7.594,31$ & $6.251,65$ & $3.625,71$ \\
\hline RA/UTH (R\$/UTH ano) & $23.863,97$ & $19.828,08$ & $27.020,29$ & $32.325,40$ & $34.909,05$ & $23.822,05$ \\
\hline Ki (R\$) & $1.320 .742,93$ & $91.564,52$ & $116.980,99$ & $60.476,75$ & $63.355,89$ & $90.752,25$ \\
\hline TL (\% ano) & 21,5 & 19,3 & 24 & 45 & 37 & 52 \\
\hline PBB/PBT (\% ano) & 99 & 71 & 67 & 53 & 40 & 80 \\
\hline PBB (R\$) & $1.085 .900,00$ & $19.203,33$ & $25.200,00$ & $16.800,00$ & $17.342,83$ & $64.113,17$ \\
\hline CI (banana) (R\$) & $363.680,50$ & $6.688,10$ & $9.758,58$ & $4.635,50$ & $8.921,13$ & $19.243,33$ \\
\hline VAB (banana) (R\$) & $722.219,50$ & $12.515,23$ & $15.441,42$ & $12.164,50$ & $8.421,71$ & $44.869,83$ \\
\hline UTH (banana) (UTH) & 13,59 & 0,82 & 0,94 & 0,84 & 0,69 & 1,77 \\
\hline SAU (Banana) (ha) & 42,00 & 4,83 & 4,83 & 2,07 & 2,50 & 9,10 \\
\hline SAU/UTH (banana) (ha/UTH) & 2,94 & 6,15 & 5,88 & 2,50 & 4,29 & 5,59 \\
\hline VAB/UTH (banana) (R\$/UTH) & $47.814,47$ & $14.282,04$ & $19.030,62$ & $14.790,00$ & $11.123,48$ & $23.978,42$ \\
\hline VAB/SAU (banana) (R\$/ha) & $13.108,73$ & $2.522,13$ & $3.201,45$ & $6.114,85$ & $3.177,96$ & $4.832,79$ \\
\hline
\end{tabular}

Fonte: WIVES (2008). 